This item was submitted to Loughborough's Research Repository by the author.

Items in Figshare are protected by copyright, with all rights reserved, unless otherwise indicated.

\title{
A multilevel approach to research 'Obscure' innovation processes and practices
}

PLEASE CITE THE PUBLISHED VERSION

http://dx.doi.org/10.21606/drs.2016.371

PUBLISHER

Design Research Society

VERSION

VoR (Version of Record)

\section{PUBLISHER STATEMENT}

This work is made available according to the conditions of the Creative Commons Attribution-NonCommercial 4.0 International (CC BY-NC 4.0) licence. Full details of this licence are available at: http://creativecommons.org/licenses/by-nc/4.0/

\section{LICENCE}

CC BY-NC 4.0

\section{REPOSITORY RECORD}

Chatzakis, Emmanouil, Neil Smith, and Erik Bohemia. 2019. "A Multilevel Approach to Research 'obscure' Innovation Processes and Practices". figshare. https://hdl.handle.net/2134/22380. 


\title{
Future-Focused Thinking
}

\section{A Multilevel Approach to Research 'Obscure' Innovation Processes and Practices}

\author{
Emmanouil Chatzakis $^{\mathrm{a} *}$, Neil Smith $^{\mathrm{b}}$ and Erik Bohemia ${ }^{\mathrm{c}}$ \\ ${ }^{a}$ Teesside University \\ ${ }^{\mathrm{b}}$ Northumbria University \\ 'Loughborough University \\ *E.Chatzakis@tees.ac.uk \\ DOI: 10.21606/drs.2016.371
}

\begin{abstract}
The paper's aim is to discuss a need for a multilevel research approach to investigate innovation practices in organisations. We argue that this approach overcomes some of the limitations of the single level research methods commonly used investigating innovation performance and success. Specifically, the multilevel research approach allows researchers and subsequently organisations to take into consideration 'obscured' practices within innovation processes. First, we put forward a motion that innovation processes permeate the formalised organisational structures and practices. Then, we outline a case where many of the practices associated with innovation are 'obscured'. This is followed with discussion on how the commonly used single level research methods fail to take into consideration these obscured factors. We then introduce Activity Theory and propose a multilevel framework which aims to overcome the shortfalls of the previous analytical methods.
\end{abstract}

Keywords: Activity Theory, New Product Development, Analytical Methods, Organisational Agility

\section{Context: The impact of obscurity in organisational practices}

Research suggests that organisations ${ }^{1}$ are struggling to sustain an organic and long-term growth and resilience in the increasingly hypercompetitive market conditions and increased and unprecedented rate of change at all levels of society ${ }^{2}$ (Johannessen, Olsen, \& Lumpkin, 2001; NESTA, 2006). Bessant, Francis, Meredith, Kaplinsky, and Brown (2001) suggested that companies will need to become agile. Bohemia and Harman $(2008$, p. 56) stated that the

\footnotetext{
${ }^{1}$ Organisations referred to throughout this study concern specifically industrial, commercial and manufacturers.

${ }^{2}$ Such as in the economic climate, environmental challenges, demographic and organisational changes.
} 
"agile manufacturing is underpinned by four key principles: delivering value to the customer, being ready for change, valuing human knowledge and skills, and forming virtual partnerships". It is proposed that agile practices will enable organisations to act more proactively, flexibly and rapidly in order to meet emerging challenges and opportunities through innovative responses. More precisely, Bessant et al. (2001) outlined that companies will need to creatively respond to these two critical continuously shifting arenas:

1. The internal (to the company) efforts to constantly search for applications of own expertise and resources into developing a new product that may ultimately be used by others (e.g. customers), and

2. To do this within a highly uncertain external environment with little or no control over important events (that may be taking place on the other side of the world) and/or other actors' behaviours, and to manage to actually sell the new product in the end.

Prior research in design, innovation and organisational analysis have discussed the existence of phenomena related to innovation processes which remain 'informal', 'hidden', 'invisible' or 'silent' within organisational practices (e.g. Gorb \& Dumas, 1987). The argument is that these 'hidden practices' are often overlooked, unrecognised. This is either because there is a certain level of tacitness (Nonaka \& Takeuchi, 1995), people are too involved and activities are too familiar or the metrics used to measure them are not 'sensitive' enough to capture them. Put it differently, there exists a certain level of obscurity attached to them. For instance, a great deal of organisational success is said to rely heavily on practices such as strong interpersonal and informal relationships and their ability to cleverly make use of resources to compete within established or niche markets (S. King \& Ockels, 2009). The informality and spontaneity surrounding the activities of organisations means that many phenomena are extremely difficult to be captured into a so-called 'objective' data (Edwards, Delbridge, \& Munday, 2005; Watkins-Mathys \& Lowe, 2005). For example, Krackhardt and Hanson (1993, p. 104) pointed out that "if the formal organisation is the skeleton of a company, the informal is the central nervous system driving the collective thought processes, actions, and reactions of its business units". Therefore, whilst it is logical to suggest that all organisations possess a certain level of structure reflected by functional / departmental roles that an organisation's members occupy as well as in formal documents such as manuals, organizational charts, training programmes and job descriptions, they only represent the tip of the iceberg of organisational life. These are unlikely determinant factors and as such do not sufficiently reflect how organisations actually operate in reality. Neither fully represent how innovation activities are carried out. This view is also shared, for instance, by socio-technical advocates like Macpherson and Clark (2009, p. 553) who noted that:

"Documented procedures provide a useful point of reference, but they cannot capture the complex unfolding nature of work and the tacit practices employees develop over time as they solve practical problems in their day-to-day employment." 
This is particularly important because in times of uncertainty and rapidly changing environments, organisational practices are constantly challenged and undergo changes which are not reflected by the formal organisation. Therefore, factors impacting on agility and innovation are said to remain often either 'invisible', or simply ignored by organisations and researchers (Nonaka \& Teece, 2001; Weick \& Sutcliffe, 2007).

This also highlights the case with many innovation tools, analytical screening models, and over-codified processes (e.g. ISO standards) recommended by experts, that often struggle to cope with the swift transformations and typical heterogeneity of many organisations, or worse, becoming a routine 'to-do' tasks, which impacts on creativity and forward thinking (Verganti, 2009). According to Nonaka and Teece (2001), studies on the way work is usually conducted in many organisations differs significantly from how it appears in job descriptions and manuals, and has both 'invisible' and collective characteristics. Verganti (2009) noted that during his study of Italian manufacturing SMEs, his understanding of what was going on within the organisations was the biggest challenge he had to overcome as "the innovation process of these organisations was tacit, invisible - no methods, no tools, and no steps" ( $p$. 8). Similarly, Miles and Green (2008) in NESTA's research report introduced the notion of 'hidden innovations' that are "not recorded using traditional innovation indicators such as research and development (R\&D)" (p. 6). This can be problematic for organisations which find it difficult to identify or even understand the sources of their relative strengths. For instance, a great deal of an organisation's activities during innovation making (i.e. New Product Development) involves unstructured phases (e.g. 'ad-hoc problem solving' Winter (2003) such as during idea generation phase during which the outcomes are still uncertain, and the activities involved are inherently non-routine (Anssi, 2010).

Meanwhile, there is much anecdotal and empirical work that discusses, a) factors promoting agility and innovation in organisations, $b$ ) the challenges associated with managing the process of innovation making and, c) prescriptive guidelines for 'best practices' to New Product Development (NPD) success. This paper does not seek to challenge these or identify new ones. Rather, the paper aims to explicate the underlying phenomena facilitating agility and innovation making by consolidating and aligning these to the dynamic contexts where they emerge. More precisely, the paper seeks to introduce a multi-level, practice-based methodological approach that will enable design researchers to take into consideration 'obscured' organisational processes and associated practices in order to enable organisations to increase their awareness and, hence, better manage their innovation potential. By obscure processes the paper refers to those practices that have been previously described as hidden, invisible or tacit and as a means to adopt a more pragmatic term (something that is not well articulated but can be found and recorded) as opposed to implying that they are 'hidden' therefore one cannot study them.

\section{Limitations to single level analyses}

Studies around agility and innovation has been done from a variety of perspectives and according to a particular level of analysis. For example, psychological theories have been 
applied to individual and/or group/team level, management theories to the organisational level, and economic theories to industrial, sectorial and overall societal level (Crossan \& Apaydin, 2010). This line of enquiry is the dominant approach to study organisational performance and innovation and has been previously termed as variance-based research (see e.g. Van de Ven \& Poole, 2005; Wolfe, 1994). As mentioned earlier, an exhaustive list of factors that impact on the agility and innovativeness of organisations is not the focus of this paper as these have been systematically reviewed elsewhere (e.g. Crossan \& Apaydin, 2010). What matters here is that a single level approaches have the notion of treating each level in isolation, hence impeding useful insights about their inherently interrelations and the influence they have on each other (Chatzakis, 2015; Gupta, Tesluk, \& Taylor, 2007) For instance, research at the organisational and external level (usually termed as macrolevel, see Figure 1) generally discount social and relational phenomena when analysing various factors such as: structures, resources, capabilities, policies; even though they also affect innovation processes and outcomes (Felin \& Foss, 2005). In general, there exists a diverse range of theories and perspectives such as the structuralist perspective, the resource-based and dynamic capabilities view of the organisation, the knowledge creation and learning organisation, and more recently social network and practice-based perspectives (Lam, 2005; Nooteboom, 1999; Pettigrew \& Fenton, 2000; Sears \& Baba, 2011). There are various distinctive differences as well as complementarities to the theoretical enquiry of each perspective (Fagerberg, Mowery, \& Nelson, 2005). One notable distinction is about their level of enquiry; some pay attention to aspects such as structures, resources and capabilities (termed here as 'resource-based'), whilst others to human aspects such as knowledge flows, relationships, interactions, situations, boundaries and the social practices underpinning organisational life (Chatzakis, 2015; Lam, 2005; Lazonick, 2005).

Notwithstanding the significant contribution of the resource-based approaches to organisational performance (and innovation), these theories have been criticised on a number of occasions. For instance, they remain somewhat abstract concepts due to the lack of a dynamic conceptual framework that would analyse the phenomena beyond the resource-based view. According to the resource-based view, for an organisation to enjoy sustained competitive advantage, an implemented strategy must nurture those resources that create value for the organisation against competition whilst remaining rare, imperfectly imitable and non-substitutable by other organisations (Stevens, 2009). For instance, design is often described as such a core inimitable capability that is linked with a company's success; it adds value to the company by providing high levels of customer satisfaction, commercial advantage through product differentiation and directing its offerings to a variety of markets (Moultrie, Clarkson, \& Probert, 2007; Stevens, 2009; Walsh, 1996). It has been argued that the resource-based view lacks a "perspective on why and how some organisations rather than others accumulate valuable and inimitable resources, or indeed what made these resources valuable and inimitable" (Lazonick, 2005, p. 33). In a post-reflection of his earlier work, Barney, Wright, and Ketchen (2001) contented that, whilst managers may assume they know which particular resources are sources of sustained competitive advantage in 
their organisation, in reality, such knowledge remains extremely obscure, as the link between resources is likely to be uncertain and ambiguous. For instance, Barney (1991) emphasized the role of social agency by suggesting that many 'imperfectly imitable' resources regard very complex social phenomena such as the interpersonal relations amongst the organisation's members, its culture, or the organisation's reputation in the external environment, all of which are very tricky to measure and systematically manage. Whilst many organisations may possess the exact same technological resources and capabilities, their effective exploitation often depends on other intangible resources, such as social relationships, quality of interactions, coordination mechanisms, and the culture and traditions of each organisation (Pettigrew \& Fenton, 2000).

On the other hand, research at the micro-level (individuals and/or groups, teams, see Figure 1) tends to overlook the effect that both internal (organisational) and external (environment) contexts impose on the innovation process (Bessant et al., 2001; Sears \& Baba, 2011; Slappendel, 1996). Traditional economic theory has been criticised as emphasizing what people are supposed to do in order to achieve 'optimal outcomes', yet forgetting that humans are far from ideal and rational beings (Fagerberg, 2005). Micro-level studies often examine the actions of certain key individuals (e.g. leaders) without taking into consideration either membership in its entirety (N. King, 1990) or the contextual and other environmental factors that influence their actions. Organisations are systems made out of bundles of people and therefore it is them who determine the willingness and ability of an organisation to innovate. Studies that adopt a single level perspective possess an important weakness in that they paint an incomplete picture of the mechanisms that influence organisational innovation practices. Lack of sensitivity to obscure micro-processes and their dynamic links with other phenomena influencing organisational performance suggests theoretical and methodological deficiencies, which considerably affect our understandings of the dynamics of their innovation practices, leaving an important gap in knowledge with several implications for potential investment and support towards them. Therefore, we suggest the need for the adoption of a multi-level approach where key phenomena may be explored incorporating a multipoint of view (Figure 1). This need builds upon calls made by other scholars who have previously supported the view that multi-level approaches are beneficial for the study of organisational agility, innovation and its associated processes (e.g. Andriopoulos \& Lewis, 2008; Gupta, Tesluk, \& Taylor, 2007; Klein, Tosi, \& Cannella, 1999; Nooteboom, 1999; Sears \& Baba, 2011; Woodman, Sawyer, \& Griffin, 1993). 


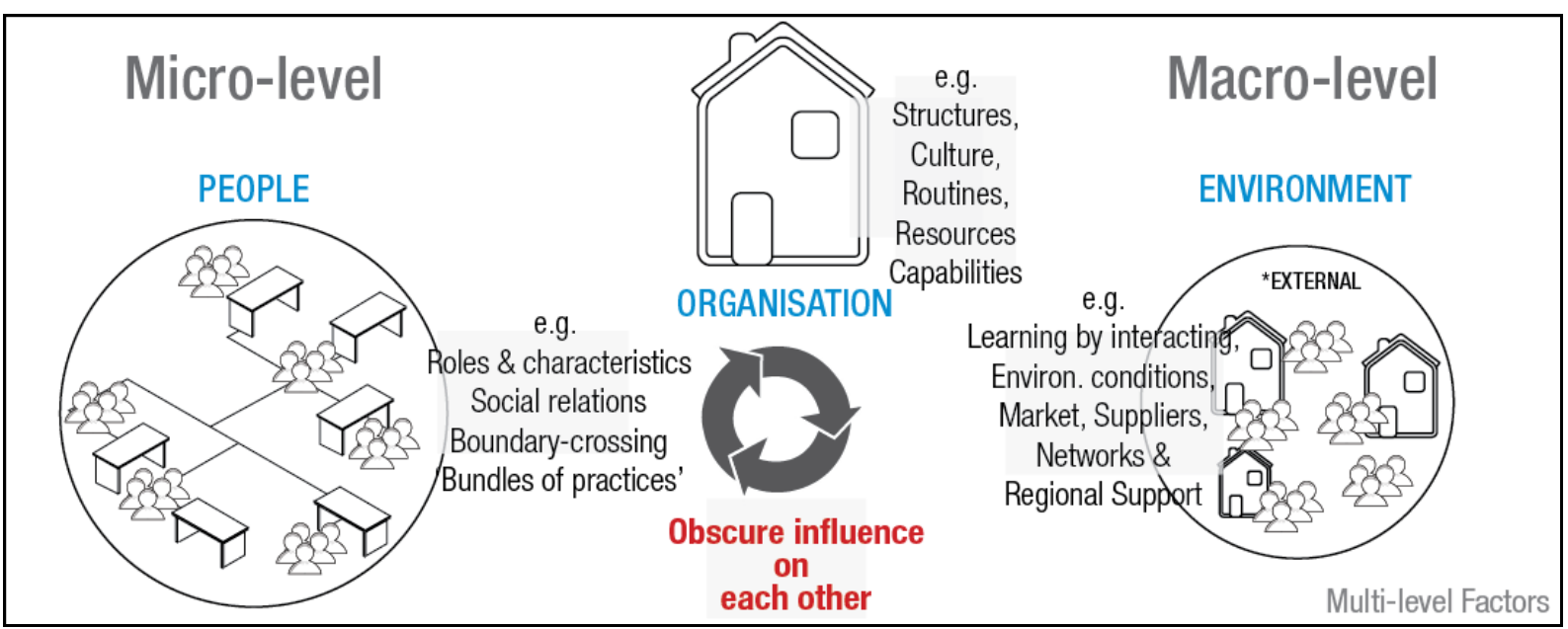

Figure 1. Illustration of micro and macro-level determinants that are suggested to facilitate agility and innovation

\section{Process: Towards a situational, contextual, relational generic process model of innovation making}

Van de Ven and Rogers (1988) centred their focus on aspects impacting the innovation process to five central concepts; a) ideas, b) people, c) transactions, d) context and e) outcomes. According to them, the innovation process progresses from "the invention and implementation of new ideas, which are developed and carried by people who engage in transactions (relationships) with others, over time and within an institutional context, and who judge the outcomes of their actions" (Van de Ven \& Rogers, 1988, p. 639, original in italics). According to this view, innovation making, in its broader sense, is fundamentally an organisational phenomenon that involves simultaneously at least two levels; i) the actor(s) which might be an individual, a team and/or an organisation, and ii) a context (both internal and external) where the actors operate in (Gupta et al., 2007). Hall (1987; cited in Hofmann, 1997, p. 723) defined organisations as:

“... a collectivity with a relatively identifiable boundary, a normative order, ranks of authority, communication systems, and membership-coordinating systems; this collectivity exists on a relatively continuous basis in an environment and engages in activities that are usually related to a set of goals; the activities have outcomes for organizational members, the organization itself, and for society."

A fundamental question that can be said to matter most in innovation research is, of course, to understand how companies innovate. As opposed to the variance approach, this line of enquiry adopts a temporary-based, process approach (Mohr, 1982; Van de Ven \& Poole, 2005). One way to demystify innovation in its making is to look at the process through which new outcomes, whether tangible or intangible, are created. New Product Development (NPD) may be seen as the ultimate end-goal for every organisation, in the sense that organisations exist, to a great extent, to serve - that is, to provide tangible and/or intangible goods and services to their 'customers'. These goods are critical to the survival, resilience and/or growth of these (and other) organisations, because new developments add to their 
economic viability as well as differentiates them from competition through attractive and pleasant products that people are more likely to choose to buy (Brown \& Eisenhardt, 1995). The term 'New Product Development (NPD)' is used here to describe the process through which new products are developed in organisations. However, it is common for scholars from other disciplines to adopt a different terminology, such as 'new product design' by engineers and designers (although Moultrie, Clarkson, \& Probert, 2007 clearly posited 'design process' as a distinguished phase within NPD) and 'innovation process' by those in R\&D domain, For reasons of simplicity and to reflect the interdisciplinary nature of NPD, this paper employs the terms interchangeably (Hart, 1995).

NPD processes trigger the mobilisation, reconfiguration and adaptation of an organisation's capabilities and resources to effectively respond to internal and external needs and, in doing so, lead to the development of different types of novel outcomes. Hence, there is a general agreement that a high-quality NPD process and proficiency in managing and executing it is important for organisations (Cooper \& Kleinschmidt, 1995; Molin-Juustila, 2006). Some of the reasons for the above assertion include the decreased cycle time and increased innovation productivity as well because it "determines the degree to which businesses can meet and/or exceed demand, and thus succeed" (Harmancioglu, McNally, Calantone, \& Durmusoglu, 2007, p. 400). This recognition has led to the substantial amount of research interest in the dynamics of NPD (e.g. Cooper, 1996, 1999; Cooper \& Kleinschmidt, 2007; Hart, 1995; Moultrie et al., 2007).

One common attribute to the process of innovation making (i.e. NPD) is the notion of uncertainty (Fagerberg, 2005) and the inherent risks, unpredictable and highly complex nature of the various multifunctional activities involved there (Moultrie et al., 2007). Saren (1984) argued that this recognised complexity highlights not only the difficulties organisations face in managing the process, but also to outsiders in studying and understanding it. For this reason, models of the process have been created with the goal to know the 'what', why', 'how' and 'where' type of activities and construct a better understanding of these activities for both their management and improvement (Tidd \& Bessant, 2009). Tidd and Bessant (2009) suggested that instead of looking at process models as descriptions or prescriptions of how the process actually operates, it would be better (especially for researchers) to look at them as 'frameworks for thinking'. This way, the task would be to develop general representations of the process, yet flexible enough in order to enable the analysis of the process "in terms of activities, functions, decisions, information flows, input and outputs, internal and external actors, or as complex network of relationships" (Saren, 1994, p. 638).

Van de Ven, Polley, Garud, and Venkataraman (1999) offered a relatively simple framework of the innovation process. The authors labelled it as the innovation journey and organised it into three main periods; initiation, development and implementation/termination where various actions and events take place. Through their longitudinal case study research where the authors explored a number of different innovation outcomes, they challenged many assumptions attached to process models. For example, Van de Ven et al. (1999) supported 
the view that innovation making has a historical aspect to it. In what they termed as a gestation period, the authors suggested that innovation making does not necessarily initiate as a result of intentionally directed activities towards innovation. Rather, the authors identified a period (i.e. gestation) during which a number of events are triggered leading to the 'Initiation' of innovation process. Closely relating to Zaltman, Duncan, and Holbek's (1973) discussion about the total change process, the gestation period according to Van de Ven et al. (1999), contains diverse events ('shock events') such as declining organisational health to changes in ownership, product failure, change in environmental conditions, the general society, various technological breakthroughs and so forth. In effect, these events generate a degree of awareness of threats and/or opportunities for the organisation which often then lead to activities triggering innovative responses. However, as ideas proliferate, the initial recognition of an opportunity for innovation (of any type) may not result in the form that was originally conceived. This is because, as Van de Ven et al. (1999) contended, the decisions made by key organisational members about a particular course of action could, occasionally and coincidentally, intersect with the courses of action of other actors (internal or external level) and lead to the realisation of new opportunities or resources. Therefore, incorporating political elements into the process. Hence, Van de Ven et al. (1999) postulated that the decision to proceed with the development of an innovation is rarely the result of a sudden spark of inspiration. Rather, the decisions that lead to innovations are dynamically and non-linearly cultivated by lengthy precipitating events, where multiple and coincidental sources of influence may come into play and cumulatively trigger the recognition of (new) opportunities. Van de Ven et al. (1999) also recognised the link between innovation and learning, albeit they also noted that "much of the outcome is due to other events which occur as innovation develops - often making learning 'superstitious' in nature" (Tidd, 2006, p. 3).

What differentiates Van de Ven et al. (1999)'s framework from standardised process models is that it recognises that "the progress of any particular innovation along this journey will depend on a variety of contingent circumstances; depending on which of these apply, different specific models of the process will emerge" (Tidd \& Bessant, 2009, p. 67). This recognition makes Van de Ven et al. (1999)'s conceptual model a satisfactory general framework for the analysis of the NPD process, as it provides enough flexibility to adapt to different organisational contexts. Figure 2 depicts the NPD process model in connection with instances of obscure multi-level phenomena described earlier that impact on agility and innovation. 


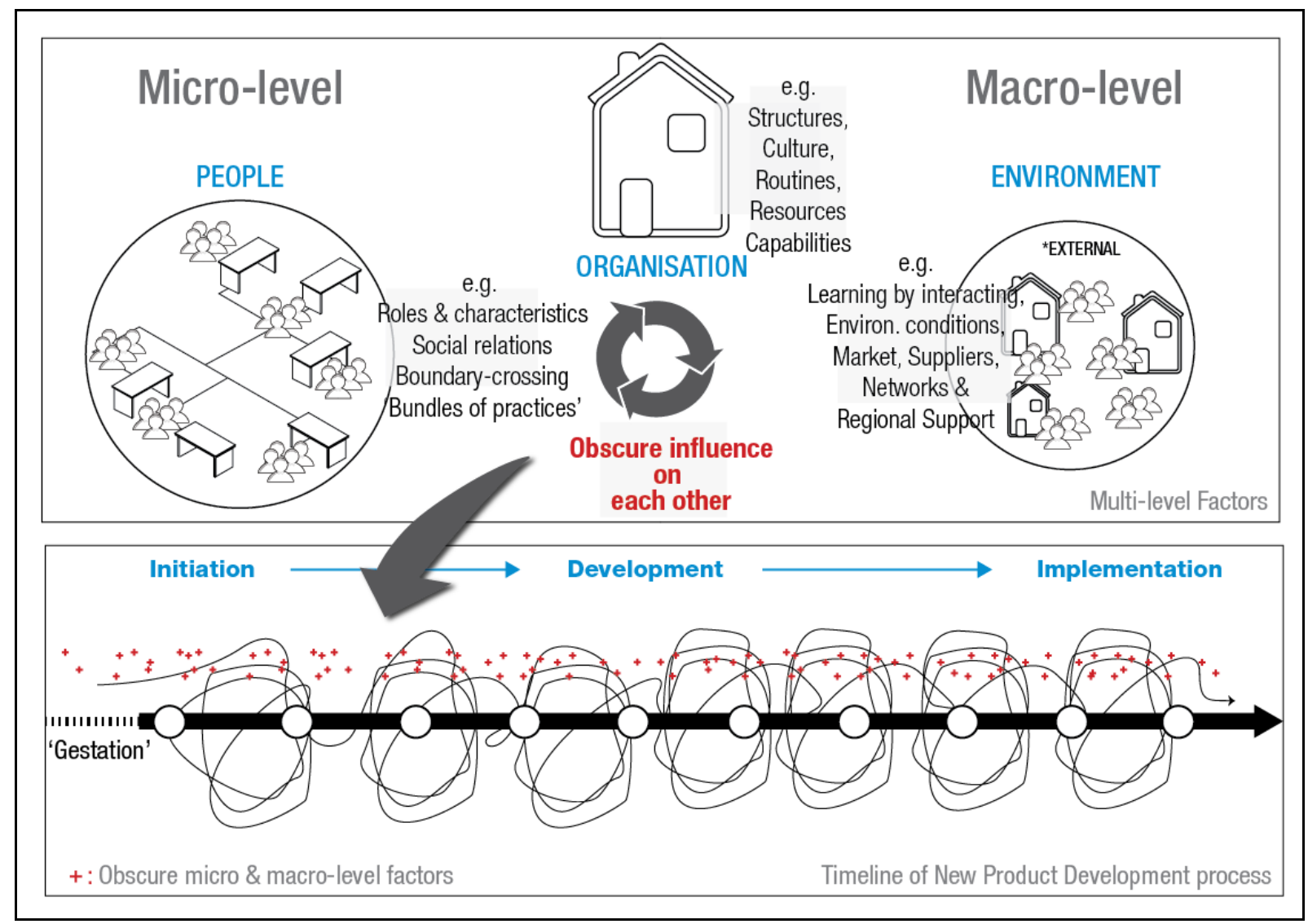

Figure 2. A general NPD model interpreted by Van de Ven et al. (1999)'s model of the innovation journey; the figure depicts the rather messy, complex and non-linear progression between the three key periods of development

\section{Towards a practice-based approach}

Recent theoretical and methodological approaches to study organisations focus on social theories that have taken a 'practice turn' for conceptualising agency and action (Chia \& Holt, 2006). In general, the concept of 'practice' has been a central investigation of the social sciences and practice theorists (e.g. Schatzki, Knorr-Cetina, \& Savigny, 2001), and increasingly the attention of management research (Tsoukas \& Yanow, 2009). For the former, practice is seen as a social phenomenon in which "the social is [...] embodied, materially interwoven [...and] centrally organised around shared practical understandings" and thus "actions are embedded in practices, just as individuals are constituted within them" (Schatzki et al., 2001, p. 3). Moreover, according to Tsoukas and Yanow (2009, p. 1347) "practitioners acquire and develop their skills in the contexts of practices, such that theorising must engage practitioners acting in the context of broader activity sets, rather than merely focusing on their individual attitudes and beliefs". Therefore, it can be asserted that as practices are socially and contextually situated within a given unit of analysis, i.e. the organisation, so are the characteristics and needs of the different organisations, dependant on their idiosyncrasies. 
This 'relational' (see e.g. Cooper, 2005) turn has shifted its emphasis away from what has being coined as methodological individualism (Chia \& Holt, 2006). This view suggests that social phenomena may be best explained "in terms of actor intentions and motivations" (ibid, p. 638), towards an emphasis to "the primacy of relationships over individual entities" and recommends that "practices are social sites in which events, entities and meaning help compose one another" (ibid, p. 640). Hence, innovation determinants such as organisational knowledge creation, sharing and learning are understood as the product of social action, interaction and habituation amongst the organisational members situated within a social system (Gherardi, 2009; Higgins, 2009; Lave \& Wenger, 1991; Macpherson \& Clark, 2009; Nicolini, Gherardi, \& Yanow, 2003; Schatzki et al., 2001). In this vein, Marshall (2008, p. 414) asserted that:

“...practice based theories adopt a more holistic, constructionist position in which the various elements of thinking, doing, and being, and the social, cultural, historical and material settings within which they are actively situated, are conceived in relationships of co-constitution."

Consequently, the practice-based ${ }^{1}$ tradition offers a potential contemporary platform for addressing issues of organisational practices and innovation "in such a way that the richness and depth of the phenomenon is given full consideration" (Nicolini et al., 2003, p. 26). In this way, research in this area can explore the complex dynamics of organisational practices from the participant's point of view, yet construed as 'bundles of practices' instead of isolated entities (Chia \& Holt, 2006; Schatzki et al., 2001).

However, as Nicolini et al. (2003, p. 12) stressed "there is no such thing as a unified practice theory or practice-based approach, only a number of research traditions and scholars connected by a common historical legacy and several theoretical family resemblances". For example, the authors provided four examples of such practice-based approaches. These adopt: i) a cultural interpretive framework, ii) a symbolic interactionist perspective through the lenses of legitimate peripheral participation also known as 'communities of practice' (Lave \& Wenger, 1991), iii) a sociology of translation also known as actor network theory (ANT) (Latour, 2005), and iv) a social constructivist theory of the cultural and historical activity theory (CHAT - more contemporarily known as Activity Theory (AT) (Engeström, 1987). One key resemblance of these four, otherwise unique, traditions is their contextual and culturally situated theorising of practice.

\subsection{Activity theory}

Activity Theory has its roots in Cultural Historical Activity Theory (CHAT) which has a long historical association with the works of developmental psychology Soviet scholars such as Leont'ev (and his concept of activity) and Vygotsky (and his concept of mediation) (Blackler, Crump, \& McDonald, 2003). The theory's most current form can be found in particular in Engeström's work (1987). Activity Theory has attracted major interest in other areas apart

\footnotetext{
${ }^{1}$ It is important to highlight here that practice-based theories in this study have a social science philosophical grounding rather than practice-based design research (see e.g. Sevaldson, 2010; also Yee, 2010).
} 
from psychology such as in educational and learning studies (see a notable review of empirical studies in Daniels, Edwards, Engeström, Gallagher, \& Ludvigsen, 2010), and increasingly in organisational and management research (e.g. Macpherson, Kofinas, Jones, \& Thorpe, 2010).

In design research scholars have adopted Activity Theory as a model to analyse activities in order to, for instance, improve the design of user interfaces in the human computer interaction paradigm $(\mathrm{HCl})$ (e.g. Kaptelinin, 2012), the design of services (e.g. Sangiorgi \& Clark, 2004) and develop computer systems for aiding product design (Tuikka, 2002). Recent calls in design research, such as in design engineering (Cash, Hicks, \& Culley, 2015) and the graphic design field (Tarbox, 2006) have particularly stressed the usefulness of Activity Theory as a framework for studying design practices from the contextual perspective it offers. As it will be further asserted in the following section, some of the key strengths that make Activity Theory stand out from other practice-based research methods are: first, Activity Theory does not rule out other practice-based theories ${ }^{1}$, rather it provides a framework that expands on them (Tarbox, 2006) and second, Activity Theory offers a visual model (that other practice theories do not) that enables a holistic analysis of the context and the multilevel phenomena influencing the activity process (NPD) as these are experienced from the members' point of view (Cash et al., 2015). Due to its historical link with developmental psychology, Activity Theory draws on heavy conceptual tools and therefore this paper will discuss only those concepts that have immediate relevance to its scope. The main goal of Activity Theory is to analyse development within practice through the social and contextual activities in which people develop their skills, personalities and consciousness (Sannino, Daniels, \& Gutierrez, 2009). According to this theory, human activity has a structure with a number of components; there is an active subject whose activity is directed towards an object mediated by tools and signs while rules influence the subject's relation to his community and the division of labour in the community's relation to the object (Tuikka, 2002). Mediation and relationships between these central components form an Activity System (Figure 3), which can be seen as:

"...the subject or group of subjects, which through mediating artefacts (concrete tools and signs) orientate their collective activity to a specific object. When the mediating artefacts change the object can appear different. Activity is always collective, thus it is constructed by a certain community and distribution of work as well as rules (written and unwritten)." (Engeström, 1987; cited in Kallio, 2010, p. 34)

\footnotetext{
${ }^{1}$ Such as Lave and Wenger (1991)'s communities of practice - see Bjørk (2004); also Engeström, Miettinen, and Punamaki (1999, p. 12).
} 


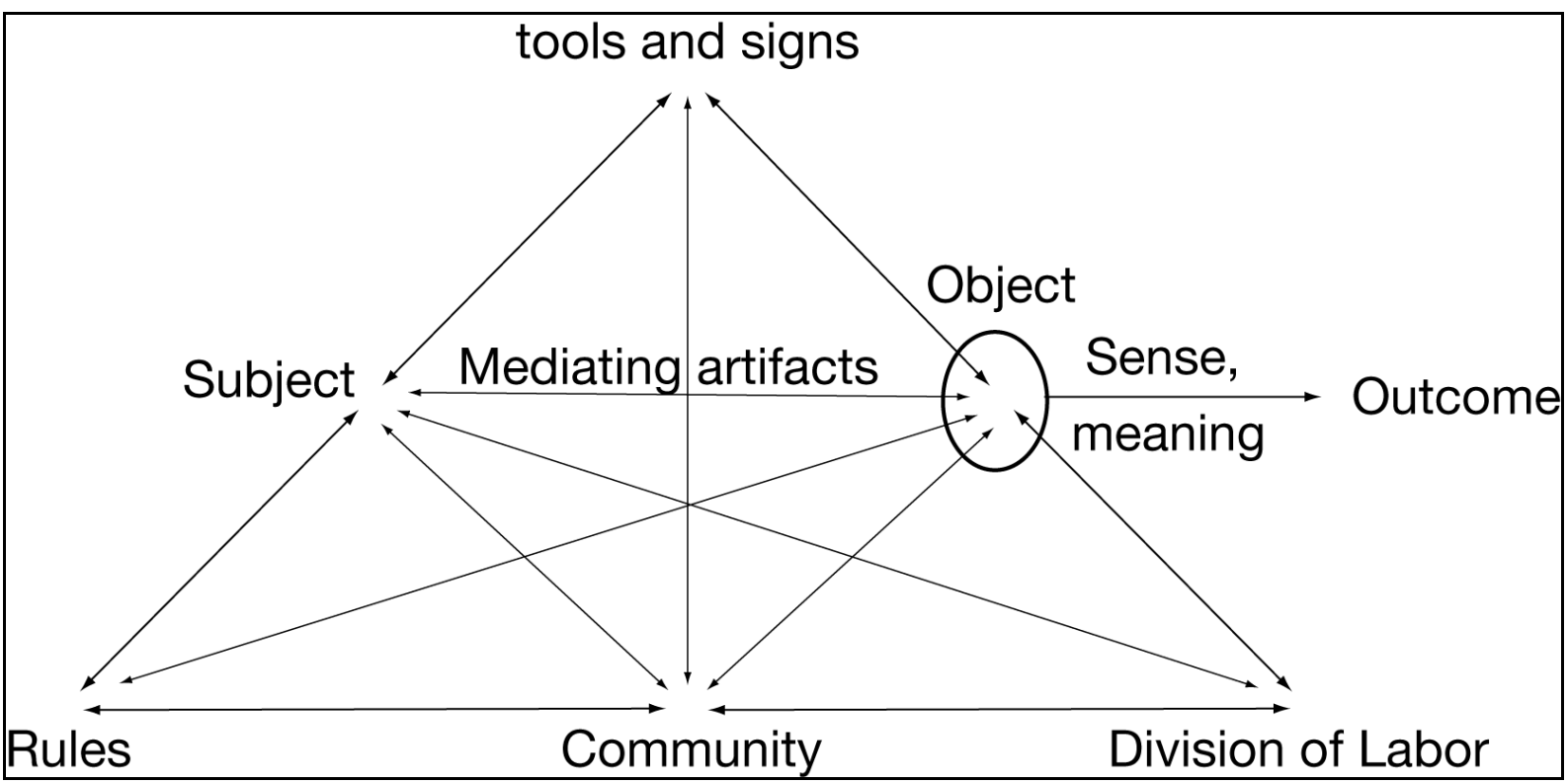

Figure 3. The structure of a human activity system according to Activity Theory (Engeström, 1987; found in Engeström, 2001, p. 135)

According to Kallio (2010) the object of activity can be seen as the 'true' motive of an activity and provides a model through which the different activities can be observed "from the point of view of an individual subject or group as collective, object-oriented and mediated by culturally produced artefacts" (Kallio, 2010, p. 33). An object can be either tangible (e.g. a product), less tangible (e.g. a drawing) or entirely intangible (e.g. a concept) (Tuikka, 2002). The culturally produced artefacts may include "tools, procedures, regulations, processes, concepts and accepted practices" and "represent the experiences of those who have solved problems in the past" and hence performance may only be achieved through their collective acceptance (Macpherson et al., 2010, p. 305). In other words, tools are "created and transformed by people during the development of the activity itself and carry with them a particular culture - historical remnants of that development" (Tuikka, 2002, p. 56). The relationship between subject and the tool can be inversely related as the tool can be both enabling (empowering the subject to go about a certain task) and limiting (interaction is selfrestricted by the perspective that the tool allows) (Molin-Juustila, 2006). Moreover, the subjects/ individuals/groups being analysed, abide by certain rules, which can be formal and explicit, such as regulations or procedures and/or can be tacit such as norms, values, beliefs (see e.g. Schein, 2010 on organisational culture). Practice is seen as taking place within a community where other activity systems and people belong and is being shared and coordinated by some divisions of labour. Engeström (2001) also suggested that by exploring the history of the object of activity (hence, closely linked with Van de Ven et al. (1999)'s concept of 'gestation period') through which it has evolved, it may potentially offer a rich understanding of the changes that have occurred within the practices of the particular activity system, as well as the tensions (or 'shock events' in Van de Ven et al. (1999)'s terms) that led to such transformation. 


\subsection{Activity Theory's relevance to the study of organisational agility and innovation}

There are a number of observations that suggest AT as an appropriate analytical model for the study of agility and innovation making (NPD). First, the analytical model of AT takes into account "one of these pervasive and persistent issues [of] the relationship between the micro and macro levels of analysis" (Engeström et al., 1999, p. 8). As it has already been discussed in earlier sections, a multilevel approach (micro and macro) to organisational innovation is the focus of this paper. Similar to the Activity Theory approach, this paper proposes the exploration of innovation activities by looking at both the detail of the practices in question, including what people do, how they do it and with whom, as well as the context in which these practices take place, including both internal and external elements. The concept of 'object-orientated' activity in particular seems to provide a very useful tool for the analysis of the activities of the key practitioners involved in the NPD process. As an example, let us consider a new product development setting where an organisation is devising a new design output for a client.

As noted earlier, the ultimate goal for the NPD is to produce a new artefact based on given requirements devised internally or as a response to external stimuli. In most typical cases, these requirements relate to the particular market needs at which the organisation aims its products. The members of the project team are all subjects in the development process and together they form a community both internally and externally with the client / partners. Each member has his/her own personal characteristics i.e. experience, skills and so forth. For example, Tuikka $(2002$, p. 66$)$ outlined the role of the designer as subject in their participation during concept design process.

\footnotetext{
"The subjects who participate in the design sessions contribute with their knowledge and personal background. These are individual resources, which are brought into the design situation. Thus, the subjects' knowledge is composed of personal understanding of the domain, which has been accumulated during their individual history. [...] The designer reflects on this knowledge and transforms the vision of the design object according to their own reflection on the goals of the design group."
}

Every member of the project team interacts with members not only from their own functions but also with other organisational functions in a division of labour. Initially, the object at hand is an unfinished prototypical idea, which needs to be transformed in order to be ready to be handed over to the client. In NPD, an object can be seen as the actual motive that drives a new idea while being transformed into its final outcome and, in this example, the overall motive is the client's satisfaction. The relationship between object construction and final outcome may be found in the concepts, visions and images of the new products that organisational members collectively construct through their practice. In this sense, the object ultimately refers to the possibilities and courses of action of the relevant activity collectively transformed through the development process. In the different stages of NPD, the subjects carry out different kinds of actions in order to transform the object into the outcome. 
Because the activity system of these practices is ambiguous and dynamic, tensions and conflicts are often evident between diverse expertise and boundaries of the various functional groups, distributed practices and competing objectives inevitably affect the way practices co-orient and re-establish (Macpherson \& Holt, 2007). Along the process, the project team makes use of a number of tangible and intangible tools, from early ideas and strategic planning to design specifications, drawings, prototyping, testing and, finally, to a fully functional product. At the same time, these different tasks are driven by certain rules, some explicit (e.g. safety standards) and some implicit (e.g. organisational culture). As Engeström (1999, p. 381) pointed out that "this situation-specific construction and instantiation of the object of an activity system often takes the form of problem finding and problem definition".

For instance, according to Activity Theory's approach, the early phases where an organisation searches and recognises an opportunity for innovation, is conceptualised as a process of sense-making of uncertain and ambiguous events (Macpherson et al., 2010; Weick, Sutcliffe, and Obstfeld, 2005). At these early stages, the organisation does not only need to construct a new product, but the object/motive of the whole new activity system needs to be designed, including elements such as strategic vision and the business plan that will guarantee (to a certain extent) sufficient profitable prospects for that new activity to exist in the first place (Molin-Juustila, 2006). Putting it simply, the activity system during the NPD process begins as an emerging state only to slowly transform into a more stable new activity system as it progresses to the later developmental stages (Molin-Juustila, 2006) (i.e. the transition between Initiation, Development and Implementation periods).

By combining the analytical approach of Activity Theory model with the multi-level factors and NPD process model presented earlier, we propose an integrated, multilevel threelayered framework to study 'obscure' innovation practices, as depicted by Figure 4 below: 


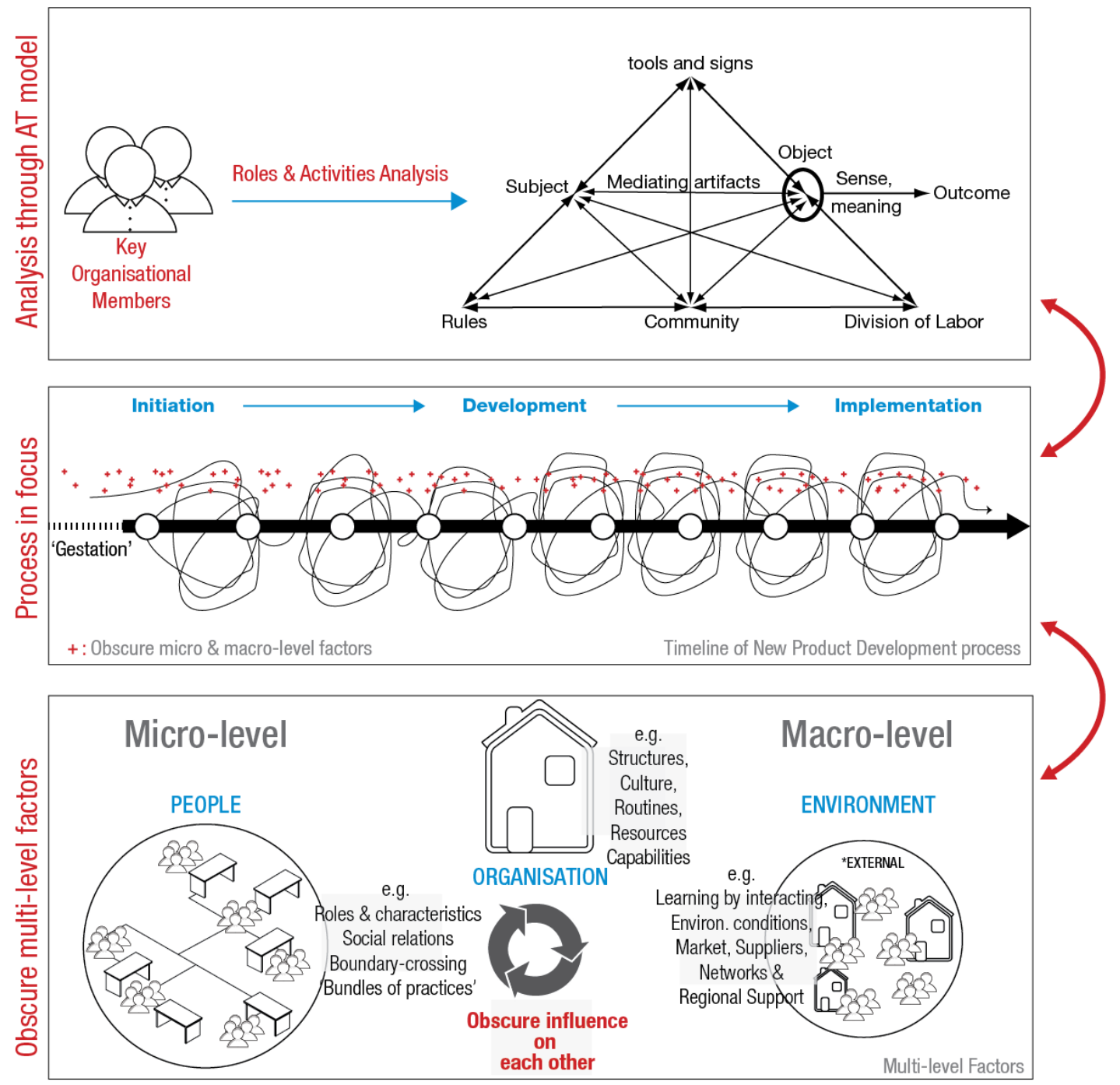

Figure 4. An integrated, multilevel framework for data collection and analysis of obscure organisational practices

\section{Conclusion}

As outlined earlier, many theoretical models, tools, services and policies both from academia, industry and government bodies exist today which aim to help achieve the conditions for organisations to become agile and innovative. Yet, the majority of these are based on prescriptive guidelines of 'best practices' that are divorced from the complex social dynamics of organisational practices which are often characterised by 'obscure innovation', i.e. not recognising the actual outcomes and the members involved in the process. This is a problem as if businesses do not fully recognise their own capabilities (or lack of them), then they will be unable to fully understand the dynamic nature of innovation practices in the unique and idiosyncratic context within their organisations. Therefore, we argue that new 
approaches are needed to better explicate the contextual, situational and relational phenomena that impact on organisational innovation practices.

Initially, the paper looked at the dichotomy between 'asking what' (variance) and 'asking how' (process) through; a) a level-based approach; people's-level (micro-level), organisational-level and external-level (macro-level) and, b) a generic model of the New Product Development where multi-level phenomena may be studied on a loose time-series and event basis. Micro and macro-levels have been well researched and documented previously. A lot less has been done with regards to how micro and macro levels interact and influence each other in the process of developing new products. In adopting a multi-level approach key organisational phenomena are seen from an interactive point of view, that is, the expected relational dependency each may have on each other. The framework is flexible enough as to be tailored and iterated according to the researcher's enquiry. Furthermore, the relatively simple NPD model (Initiation, Development, Implementation) proposed by this paper serves as a 'framework for thinking' (Tidd \& Bessant, 2009) rather than a descriptive or prescriptive representation of an ideal NPD process. This approach provides researchers with enough flexibility to adapt their enquiry to different organisational contexts; identify key phenomena that emerge at different phases in the process; reconstruct the actual process according to how organisations experience their NPD processes.

Finally, the paper argues that the analysis of the organisational phenomena underpinned by a practice-based approach and through the Activity Theory model, should enable researchers to conceptualise agility and innovation-making from a social relational, situational and contextual perspective. According to the proposed model (Figure 4), the research process starts with focusing on the NPD process and exploring the roles and activities of key organisational members through the Activity Theory model. Doing so, it should enable the identification of multi-level factors influencing practice at each point in the NPD process.

The theoretical contribution of this paper is the consolidation and investigation of the various terms and concepts from a multi-level, integrated approach that aligns together variance, process and practice-based theories. We propose that this devised research methodology may enable the construction of a more holistic picture of organisational phenomena that often remain 'obscure' in day-today practice. Future work will provide case examples of the suggested framework's application in the industry.

\section{References}

Andriopoulos, C., \& Lewis, M. W. (2008) Exploitation-Exploration Tensions and Organizational Ambidexterity: Managing Paradoxes of Innovation. Organization Science, 20(4), 696-717.

Anssi, S. (2010) Characteristics of routine, development and idea networks in teams. Team Performance Management, 16(1), 95-117.

Barney, J. (1991) Firm Resources and Sustained Competitive Advantage. Journal of Management, 17(1), 99. 
Barney, J., Wright, M., \& Ketchen, D. J. (2001) The resource-based view of the firm: Ten years after 1991. Journal of Management, 27(6), 625-641.

Bessant, J., Francis, D., Meredith, S., Kaplinsky, R., \& Brown, S. (2001) Developing manufacturing agility in SMEs. International Journal of Technology Management, 22(1), 28-54.

Bjørke, S. A. (2004) The concepts of Communities of Practice, Activity Theory and implications for Distributed Learning. Retrieved 30 January, 2011, from http://www.gvu.unu.edu/docs/The\%20concepts\%20of\%20Communities\%20of\%20Practice,\%20Ac tivity\%20Theory\%20and\%20implications\%20for\%20distributied\%20learning.doc

Blackler, F., Crump, N., \& McDonald, S. (2003) Organizing Processes in Complex Activity Networks. In D. Nicolini, S. Gherardi \& D. Yanow (Eds.), Knowing in organizations: a practice-based approach (pp. 126-150). Armonk, N.Y.: M.E. Sharpe.

Bohemia, E., \& Harman, K. (2008) Globalization and Product Design Education: The Global Studio. Design Management Journal, 3(2), 53-68.

Brown, S. L., \& Eisenhardt, K. M. (1995) Product development: Past research, present findings, and future directions. Academy of Management Review, 20(2), 343-378.

Cash, P., Hicks, B., \& Culley, S. (2015) Activity Theory as a means for multi-scale analysis of the engineering design process: A protocol study of design in practice. Design Studies, 38, 1-32.

Chatzakis, E. (2015) Maintaining Agility: A study of obscure New Product Development practices in small and medium sized manufacturing enterprises to understand how they maintain relevance to their markets. (PhD), Northumbria University.

Chia, R., \& Holt, R. (2006) Strategy as practical coping: a Heideggerian perspective. Organization Studies, 27(5), 635-655.

Cooper, R. (2005) Peripheral Vision: Relationality. Organization Studies, 26(11), 1689-1710.

Cooper, R. G. (1996) Overhauling the New Product Process. Industrial Marketing Management, 25, 465-482.

Cooper, R. G. (1999) From Experience: The Invisible Success Factors in Product Innovation. Journal of Product Innovation Management, 16(2), 115-133.

Cooper, R. G., \& Kleinschmidt, E. J. (1995) Benchmarking the Firms Critical Success Factors in New Product Development. Journal of Product Innovation Management, 12, 374-391.

Cooper, R. G., \& Kleinschmidt, E. J. (2007) Winning Businesses in Product Development: The Critical Success Factors. Research-Technology Management, 50, 52-66.

Crossan, M. M., \& Apaydin, M. (2010) A multi-dimensional framework of organizational innovation: a systematic review of the literature. Journal of Management Studies, 47(6), 1154-1191.

Daniels, H., Edwards, A., Engeström, Y., Gallagher, T., \& Ludvigsen, R. S. (2010) Activity theory in practice : promoting learning across boundaries and agencies. London; New York: Routledge.

Edwards, T., Delbridge, R., \& Munday, M. (2005) Understanding innovation in small and mediumsized enterprises: a process manifest. Technovation, 25(10), 1119-1127.

Engeström, Y. (1987) Learning by expanding: an activity-theoretical approach to developmental research. Helsinki: Orienta-Konsultit.

Engeström, Y. (1999) Innovative learning in work teams: Analyzing cycles of knowledge creation in practice. In Y. Engeström, R. Miettinen \& R.-L. Punamäki (Eds.), Perspectives on Activity Theory (pp. 375-404). Cambridge: Cambridge University Press.

Engeström, Y. (2001) Expansive Learning at Work: Toward an activity theoretical reconceptualization. Journal of Education and Work, 14(1), 133-156. 
Engeström, Y., Miettinen, R., \& Punamaki, R.-L. (1999) Perspectives on Activity Theory. Cambridge: Cambridge University Press.

Fagerberg, J. (2005) Innovation: A Guide to the Literature. In J. Fagerberg, D. C. Mowery \& R. R. Nelson (Eds.), The Oxford handbook of innovation (pp. 1-26). Oxford ; New York: Oxford University Press.

Fagerberg, J., Mowery, D. C., \& Nelson, R. R. (2005) The Oxford handbook of innovation. Oxford ; New York: Oxford University Press.

Felin, T., \& Foss, N. J. (2005) Strategic organization: a field in search of micro-foundations. Strategic Organization, 3(4), 441-455.

Gherardi, S. (2009) Knowing and learning in practice-based studies: an introduction. The Learning Organization, 16(5), 352-359.

Gorb, P., \& Dumas, A. (1987) Silent design. Design Issues, 8(3), 150-153.

Gupta, A. K., Tesluk, P. E., \& Taylor, M. S. (2007) Innovation At and Across Multiple Levels of Analysis. Organization Science, 18(6), 885-897.

Harmancioglu, N., McNally, R. C., Calantone, R. J., \& Durmusoglu, S. S. (2007) Your new product development (NPD) is only as good as your process: an exploratory analysis of new NPD process design and implementation. R\&D Management, 37(5), 399-424.

Hart, S. (1995) Where we've been and where we're going in new product development research. In M. Bruce \& W. G. Biemans (Eds.), Product development: meeting the challenge of the designmarketing interface. Chichester: Wiley.

Higgins, D. (2009) Engaging the small firm in learning: Practice based theorising on complex social knowledge. Journal of European Industrial Training, 33(1), 81-96.

Hofmann, D. A. (1997) An Overview of the Logic and Rationale of Hierarchical Linear Models. Journal of Management, 23(6), 723-744.

Johannessen, J.-A., Olsen, B., \& Lumpkin, G. T. (2001) Innovation as newness: what is new, how new, and new to whom? European Journal of Innovation Management, 4(1), 20-31.

Kallio, K. (2010) The meaning of physical presence: An analysis of the introduction of processoptimisation software in a chemical pulp mill. In H. Daniels, A. Edwards, Y. Engestrom, T. Gallagher \& R. S. Ludvigsen (Eds.), Activity theory in practice: promoting learning across boundaries and agencies (pp. 31-48). London; New York: Routledge.

Kaptelinin, V. (2012) Activity Theory. In M. Soegaard \& R. F. Dam (Eds.), Encyclopedia of HumanComputer Interaction. Aarhus, Denmark: The Interaction Design Foundation. Retrieved from http://www.interaction-design.org/encyclopedia/activity_theory.html.

King, N. (1990) Innovation at work: the research literature. In M. A. West \& J. L. Farr (Eds.), Innovation and creativity at work: psychological and organizational strategies: Wiley.

King, S., \& Ockels, C. (2009) Defining small business innovation. In Intuit (Ed.), Future of Small Business Series.

Klein, K. J., Tosi, H., \& Cannella, A. A. (1999) Multilevel theory building: Benefits, barriers, and new developments. Academy of Management Review, 24(2), 248-253.

Krackhardt, D., \& Hanson, J. R. (1993) Informal networks: the company behind the charts. Harvard Business Review, 71(4), 104-111.

Lam, A. (2005) Organizational Innovation. In J. Fagerberg, D. C. Mowery \& R. R. Nelson (Eds.), The Oxford handbook of innovation (pp. 115-148). Oxford: Oxford University Press.

Latour, B. (2005) Reassembling the Social-An Introduction to Actor-Network-Theory, by Bruno Latour, pp. 316. Foreword by Bruno Latour. Oxford: Oxford University Press. 
Lave, J., \& Wenger, E. (1991) Situated learning : legitimate peripheral participation. Cambridge: Cambridge University Press.

Lazonick, W. (2005) The Innovative Firm. In J. Fagerberg, D. C. Mowery \& R. R. Nelson (Eds.), The Oxford handbook of innovation. Oxford: Oxford University Press.

Macpherson, A., \& Clark, B. (2009) Islands of Practice: Conflict and a Lack of 'Community' in Situated Learning. Management Learning, 40(5), 551-568.

Macpherson, A., \& Holt, R. (2007) Knowledge, learning and small firm growth: A systematic review of the evidence. Research Policy, 36(2), 172-192.

Macpherson, A., Kofinas, A., Jones, O., \& Thorpe, R. (2010) Making sense of mediated learning: Cases from small firms. Management Learning, 41(3), 303-323.

Marshall, N. (2008) Cognitive and Practice-based Theories of Organizational Knowledge and Learning: Incompatible or Complementary? Management Learning, 39(4), 413-435.

Miles, I., \& Green, L. (2008) Hidden innovation in the creative industries. London: NESTA.

Mohr, L. B. (1982) Explaining organizational behavior. San Francisco; London: Jossey-Bass.

Molin-Juustila, T. (2006) Cross-functional interaction during the early phases of user-centered software new product development: reconsidering the common area of interest. University of Oulu.

Moultrie, J., Clarkson, P. J., \& Probert, D. (2007) Development of a Design Audit Tool for SMEs. Journal of Product Innovation Management, 24, 335-368.

NESTA (2006) The Innovation Gap Report. London: National Endowment for Science, Technology and the Arts.

Nicolini, D., Gherardi, S., \& Yanow, D. (2003) Knowing in organizations : a practice-based approach. Armonk, N.Y.: M.E. Sharpe.

Nonaka, I., \& Takeuchi, H. (1995) The knowledge-creating company: how Japanese companies create the dynamics of innovation. Oxford: Oxford University Press, 1995.

Nonaka, I., \& Teece, D. J. (2001) Managing industrial knowledge: creation, transfer and utilization. London; Thousand Oaks, Calif.: SAGE.

Nooteboom, B. (1999) Innovation, learning and industrial organisation. Cambridge Journal of Economics, 23(2), 127-150.

Pettigrew, A. M., \& Fenton, E. M. (2000) The innovating organization. London; Thousand Oaks, Calif.: Sage.

Sangiorgi, D., \& Clark, B. (2004) Toward a participatory design approach to service design. Paper presented at the PDC.

Sannino, A., Daniels, H., \& Gutierrez, K. D. (2009) Activity Theory Between Historical Engagement and Future-Making Practice. Learning and expanding with activity theory. Cambridge: Cambridge University Press.

Saren, M., A. (1984) A classification and review of models of the intra-firm innovation process. $R \& D$ Management, 14(1), 11-24.

Saren, M., A. (1994) Reframing the process of new product development: from "stages" models to a "blocks" framework. Journal of Marketing Management, 10(7), 633-643.

Schatzki, T. R., Knorr-Cetina, K. D., \& Savigny, E. v. (2001) The practice turn in contemporary theory. London: Routledge.

Sears, G. J., \& Baba, V. V. (2011) Toward a multistage, multilevel theory of innovation. Canadian Journal of Administrative Sciences / Revue Canadienne des Sciences de l'Administration, 28(4), 357372. 
Sevaldson, B. (2010) Discussions \& movements in design research. FORMakademisk, 3(1).

Slappendel, C. (1996) Perspectives on innovation in organizations. Organization Studies, 17(1), 107129.

Stevens, J. (2009) Design as a strategic resource. Design's contributions to competitive advantage aligned with strategy models. (PhD), University of Cambridge.

Tarbox, J. D. A. (2006) Activity Theory: A model for design research. In A. Bennett (Ed.), Design studies: theory and research in graphic design (pp. 73-81): Princeton Architectural Press.

Tidd, J. (2006). A review of innovation models. Imperial College London.

Tidd, J., \& Bessant, J. R. (2009) Managing innovation: integrating technological, market and organizational change (4th ed). Chichester: John Wiley.

Tsoukas, H., \& Yanow, D. (2009) What is Reflection-In-Action? A Phenomenological Account. Journal of Management Studies, 46(8), 1339-1364.

Tuikka, T. (2002) Towards computational instruments for collaborating product concept designers. (Thesis), Oulun yliopisto, Oulu.

Van de Ven, A. H., Polley, D. E., Garud, R., \& Venkataraman, S. (1999) The innovation journey. New York: Oxford University Press.

Van de Ven, A. H., \& Poole, M. S. (2005) Alternative Approaches for Studying Organizational Change. Organization Studies, 26(9), 1377-1404.

Van de Ven, A. H., \& Rogers, E. M. (1988) Innovations and organizations. Communication Research, 15(5), 632-651.

Verganti, R. (2009) Design-driven innovation : changing the rules of competition by radically innovating what things mean. Boston, Mass.: Harvard Business School Press.

Walsh, V. (1996) Design, innovation and the boundaries of the firm. Research Policy, 25, 509-529.

Watkins-Mathys, L., \& Lowe, S. (2005) Small business and entrepreneurship research: the way through paradigm incommensurability. International Small Business Journal, 23(6), 657-677.

Weick, K. E., \& Sutcliffe, K. M. (2007) Managing the unexpected: resilient performance in an age of uncertainty (2nd ed. ed.). San Francisco, Calif.: Jossey-Bass ; Chichester : John Wiley [distributor].

Weick, K. E., Sutcliffe, K. M., \& Obstfeld, D. (2005) Organizing and the Process of Sensemaking. Organization Science, 16(4), 409-421.

Winter, S. G. (2003) Understanding dynamic capabilities. Strategic Management Journal, 24(10), 991 995.

Wolfe, R. A. (1994) Organizational innovation: review, critique and suggested research directions. Journal of Management Studies, 31(3), 405-431.

Woodman, R., Sawyer, J., \& Griffin, R. (1993) Toward a Theory of Organizational Creativity. The Academy of Management Review, 18(2), 293-321.

Yee, J. S. R. (2010) Methodological innovation in practice-based design doctorates. Journal of Research Practice, 6(2), Article M15.

Zaltman, G., Duncan, R., \& Holbek, J. (1973) Innovations and organizations. New York: Wiley. 
About the Authors:

Dr Emmanouil Chatzakis is a part-time Lecturer in Product Design at Teesside University and a Design Researcher. He was awarded his PhD in Design in 2015 at Northumbria University. His specialities include Product and Service Design, Design Strategy, Innovation Practice, Design Methods.

Neil Smith is an Enterprise Fellow at Northumbria University. A Product Designer with over 35 years experience working across academic and business sectors, from SME's to major FMCG organisations. His specialties and research activities include; Design for Manufacture, Innovation practice within SME's, and Multidisciplinary Design Practice.

Dr Erik Bohemia is the Programme Director in the Institute for Design Innovation at Loughborough University London. He is interested in Design as a cultural practice and the material effects of design. He is currently researching the 'construction' of the user and how this guides the design process. 